\title{
Psychological Trauma Among Nigerian Undergraduates: The Role of Exposure to Crime and Fear of Crime
}

\author{
Okoye, Chukwuemeka A.F. ${ }^{1} \quad$ Obi-Nwosu, Harry $^{2} \quad$ Muodumogu, Chiamaka A. ${ }^{3} \quad$ Ezeodina, Favour O. ${ }^{4}$ \\ Faculty of Social Sciences, Department of Psychology, Nnamdi Azikiwe University, P.M.B 5025, Awka. \\ Anambra State - Nigeria
}

\begin{abstract}
Studies on psychological health of undergraduate students across the world, including Nigeria shows prevalence of psychological trauma among the students. This study examined the correlation between undergraduate students' exposure to violent crime and psychological trauma, and their fear of crime and psychological trauma. The participants were 505 undergraduates consisting of $226(45.1 \%)$ males, $266(55.1 \%)$ females and $11(2.2 \%)$ who did not indicate their gender. The participants whose ages range from 18 to 32 years, with a mean age of 23 . 47years and standard deviation of 2.31 were sampled through systematic random sampling from eight departments randomly drawn from the fourteen faculties in Nnamdi Azikiwe University, Awka. The instruments used for data generation were: Measure for Exposure to Violence developed by Engelbrecht (2009); Impact of Event Scale (IESR) developed by Harowitz, Wilner and Alvarez (1997) and fear of Crime Measure developed by Von-Klemperer (2009). The survey study employed a correlational design and used Pearson Product Momen Correlation Statistics for analysis of data. Two research questions were answered and two hypotheses tested at $\mathrm{P}<0.05$ level of significance. The two hypotheses were confirmed. The result of the study showed a significant positive relationship between undergraduate students' exposure to violence crime and psychological trauma, and between fear of crime and psychological trauma.

The researchers made recommendations which include among others, generating employment as a measure for curbing violent crime, beefing up security and developing intervention programmes that will victims to cope with fear and psychological trauma.
\end{abstract}

Keywords: Exposure, violent crime, fear, crime, psychological trauma.

DOI: $10.7176 / \mathrm{JEP} / 10-24-10$

Publication date: August 31st 2019

\section{Introduction}

Several studies on psychological health of undergraduate students (or the youths) across nations of the world, including Nigeria, shows prevalence of psychological trauma (PT) or emotional trauma or distress among them (Muhammed, Jaffei, Ismail \& Mahadevan, 2013; Geidam, Njoku \& Bako, 2010; Oner, Ozeebe, Telta \& Tezcan, 2008). Observation has also shown that people consciously or unconsciously manifest signs of trauma in their thinking, behaviour, and relationship with others. Some observed compulsive behaviour people live with may be the outcomes of psychological trauma. Instances of this include where a person vows never to travel by night again or complains of inability to sleep in a moving vehicle, this simple reason being that he had been a victim of an armed robbery attack on a night bus.

In parts of Nigeria by armed robbers, and or Kidnappers, or infested by Boko Haram Lethal activities, it is a common knowledge that people feel so insecure that many had fled their homes, business is affected, children boycott school, and the general tone of life is disturbed. These are behavioural signs of psychological trauma. There abound many instances where people lose their senses after encounter with violent armed robbers or Kidnappers or losing significant family member(s) or as an aftermath of other types of violence. Thus, symptoms of psychological trauma commonly observed in victims can be cognitive, physical, emotional or behavioural or a combination of two or more.

According to Australian Psychological Society (2015) and Psychological Care and Healing (2015), physical symptoms of psychological trauma include headache, excessive alertness (hyper-vigilance), easily startled, allergies, eating disturbances or disorders, rapid heart rate, fatigue or exhaustion, sleep disturbances, general body aches and pains. Cognitive symptoms are intrusive thoughts and memories of the event, visual images of the event, nightmares, poor concentration and memory disorientation and confusion. Behavioural symptoms include avoidance of place or activities that are reminders of the event, social withdrawal and isolation, loss of interest in normal activities and other self-destructive behaviour such as substance abuse and excessive alcohol consumption. Emotional symptoms include fear, numbness, and or detachment, depression, panic attack, guilt or shame, anger, rage, irritability, obsession with injury or death, and feeling out of control.

These symptoms are however normal reactions to trauma, once they are not too severe or long lasting. But, where they are severe and long lasting or poorly handled, the can result to more serious psychological conditions such as depression, posttraumatic stress disorder (PTSD), anxiety disorders, or substance (alcohol or drug) abuse (Australian psychological Society, 2015). 
The above conditions impact not only the health of the victims, but also their social and economic life. Lawler, Quimette, \& Dahlsent (2005), in their study on the effects of trauma on university students, agrees that trauma symptoms have relationship with poorer health status. They were of the opinion that if not healed, the student victim may go through life with psychological problems interfering with both their intrapersonal and inter-personal healthy living.

These findings made on adolescents in the western world may also apply to Nigerian adolescents, considering he many observable signs of aggression, restiveness, depression and mental cases among them. In urban cities of Nigeria, there are alarming number of mentally-ill young people who roams the street and market places. Even on campuses, students do discuss fresh incidence of fellow students, who all of a sudden start displaying signs of mental disorder.

Thus, the assumption of the researchers in that undergraduate students who have suffered psychological trauma and especially, if they were unable to cope or were not healed from the effects of trauma, may find it difficult to live the normal life at the university.

The word 'trauma' is derived from Greek word 'troma' which means 'wound' (psychological care \&Healing, 2015). Psychological trauma, also referred to as emotional trauma, describes damage to the psyche resulting from stressful or traumatic life events or experience (Psychological care \& Healing, 2015). Highly frightening or distressing events may inflict a psychological wound or injury on a person which manifest in difficulty in coping or functioning normally after a particular stressful event or experience (Australian Psychological Social, 2015).

Indeed, the experience, perception or reaction to traumatic event is subjective, meaning that an individual's perception of an experience determines whether an event is traumatic or not (Giller,1999). Thus, the DSM-IV-TR criteria defines a traumatic event as an individual's appraisal of an event as personally threatening (Engelbrecht, 2009). The reactions following the appraisal are usually influenced by the individual's emotional background, developmental history, identity, current state of psychological wellbeing and conscious or unconscious perception of the information as threatening (Psychological care \& Healing, 2015)'

The traumatic events are mostly the violent crimes and other violence of non-criminal nature that pervade the nations of the world, including Nigeria. These events may include, but not limited to natural disasters technological disasters or violence (motor vehicle and plane crashes, industrial and domestic accidents, etc) and criminal violence or disaster (armed robbery, Kidnapping, bombing, homicide/manslaughter, suicide, assassination, terrorism, killing for ritual, child abuse, human trafficking, etc).

Crimes in the context of this study were considered as the illegal and morally wrongful acts which cause harm not only to the individual, but also to the society at large. Lauer in Eugelbrecht (2009), defines violence as the use of force to harm, injure, or abuse others. This then implies that violence is criminal in nature. Hence violence is contextualized as the use of force to abuse, injure, harm or kill others.

Violent crime is known through the media to be a global phenomenon that poses serious threats to many nations of the world, though in varying nature and degree of prevalence and impact. In Nigeria, for instance, the technological violence and criminal violence are more threatening than natural violence. In the past three decades Nigeria have witnessed all manner of violent crimes (Akeen, 2008: Agbu, 2003), with staggering number of casualties, and continues to do June, 2006 to $31^{\text {st }}$ May, 2014, gave the number of violent incidences as 14,006 resulting in 60,855 deaths (Nigeria Stability and Reconciliation Programme (NSRP), 2014). The high rate of death from what could be termed carnivorous and beastly activities of ethnic militia and militant groups especially Boko Haram (criminal violence) and the high frequency of carnages on both highways and local roads through accidents (technological violence) are worrisome. Thus, violence in Nigeria has gotten to such a level that both old and young in the country are exposed to high levels of violence almost on a daily basis.

Exposure to violent crime (EVC), rather than defined, is described variedly in literature. Some researchers, for instance, have differentiated between witnessed and observed exposure, and exposure to interpersonal violence or community violence (Mrug, Loosier and Windle,2008). In this study exposure to violent crime is described as any exposure to violent events by the direct experience (being a victim), witnessing or observing, or awareness through hearing or learning of such traumatic events.

The rate of exposure to violent crime of the Nigerian populace is better imagined considering the high rate of violent crime in the country. The undergraduate students are not left out. Previous studies have established their exposure to violent crimes (Hunteington, 2012; Milligan, 2010; Listurlejska 2008; Weaver, 2005). Being part of the normal population, they are prone to experience traumatic events just like other people and even more, given that they may have other violent crimes or situations to face in the school environment.

School violence can be defined as any verbal, physical, psychological or visual manifestation intended to directly or indirectly harm, threaten or control the physical or psychological wellbeing or property of others within the school setting (Milligan, 2010). School violent acts include, bullying, threats, sexual assault, rape, fights with dangerous weapons, campus cultism (Milliganm, 2010). Some of the students may have witnessed or been directly affected by public violence and or school violence or natural calamities or domestic violence or physical sexual abuse, etc. These miserable experiences, according to Seery (2011), can cause psychological traumatisation's 


\section{which fear is inclusive.}

Fear is generally defined as an unpleasant feeling of anxiety or apprehension caused by the presence or anticipation of danger (Encarta, 2009). It also refers to frightening thoughts and worries about something unpleasant that may happen. In the context of this study, the something unpleasant is the violent crime. Fear of crim $(\mathrm{FC})$ can be described as an "emotional response of dread or anxiety to crime or symbols that a person associates with crime" (Michael in Grinshteyn, 2013, P.25). fear of crime, which refers to the fear being a victim of crime rather than being an actual victim is usually manifested in day-to-day anxiety about one's sense of safety and risk of exposure to violent crime (Pretorius, 2008) Simply put fear of crime in the amount of fear a person expresses about certain crimes (Truman, 2005). Also, Garofalo (1981), defined it as an emotional reaction mirrored by a feeling of danger and anxiety over a perceived physical harm. In essence, it refers to the dread of being a victim of crime. Fear of crime have some adverse effects which include, but not limited to negative impact on individual and public health, and wellbeing, disruption of routine activities and habits and deterioration in peace and stability in the neighbourhood. The adolescents have more than a fair share of the adverse consequences of fear of crime. They, in addition to sharing in the consequences common to all, also have other issues peculiar to them (Grinshteyn, 2013).

For instance, in a neighbourhood where most of the residents are fearful of looming crimes, recreational activities may be affected, and this affects the adolescents who do not have enough safe place to engage in outdoor recreation. In addition, these young ones who are thus forced to keep in-doors most of the time, may resort to less appropriate means of recreation, such as engagement in indiscriminate sexual activities and drug experimentation which paradoxically may dispose or expose them to the 'feared crime'. For the undergraduate students, academic activities may also be affected. Night classes are boycotted, even by those living on campus, to say nothing of offcampus students most of whom live close to the school. Involvement of students in field studies and excursions may also be affected, depending on the crime-safety of the stated destination for the study or excursion. Thus, fear of crime may adversely affect undergraduate students' physical life, intellectual performance, capacity building and social development (Beaulac, Bouchard \& Kristianson, 2013).

Several theoretical stand points have endeavoured to explain the causes of psychological Trauma. For instance, trauma theory, which derived from Canon-Bard theory of flight or fight, and abbreviated by Bcoom (1999), postulates that human beings as mammals are naturally prepared by stress hormones to respond to the threatening events when traumatized, by either fighting to overcome the threat or flee from it when it seems insurmountable. The theory also holds that human beings depend on each other for survival and psychological wellbeing, because they are social beings. Thus, the theory upholds that any disruption of this social ties may cause trauma in the victims. Furthermore, some body of theories posits that social differentiation in the risks of criminal victimization results from variation in routine activities/lifestyle which determines the proximity of individuals (victims) or their property to motivated offender (crime committers). This body of theories organized by Meith, Stafford and Long (1987), includes Routine Activity Approach by Cohen and Felson in (1979) and the Lifestyle/Exposure Approach by Hindelang GottFredo and Garofalo in (1978).

The basic assumption of Routine Activity Approach is that structural changes in activity patterns affect crime rates by influencing the meeting together in time and space of three necessary elements for criminal victimization: (a) motivated offenders (crime committers), (b) suitable targets (Vulnerable victims), and (c) absence of guardians (insecurity). The three elements are important for direct-contact violation (direct victimization) of victims (Cohen and Felson, in Miethe, Stafford, \& Long, 1987). On the other hand, Lifestyle/Exposure Approach posits that demographic characteristics- age, gender, income, marital status inter-relate with various role expectations which in turn lead to differences in lifestyle, exposure to risk, and after words to differences in likelihood of victimization.

Empirical literature revealed several studies carried out in the dependent variables of study in relation to other variables. Giaconia, Reinherz, Silverman, Pakiz, Frost, and Cohen (1995) examined trauma and posttraumatic stress disorder in a community population of older adolescents. The researchers studied 384 Eighteen Years-old U.S. adolescents in a longitudinal study, examining a large number of stressful events in the participants. The result showed that more than two-fifths of the adolescents had, by the age of 18, experienced at least one traumatic event. In a study Cebello, Ramirez, Hearn, and Maltese (2003), investigated whether children's perception of parental monitoring moderate the relation between children's exposure to violence and their psychological wellbeing, assessed by prevalence of depression and hopelessness. The study assessed data using the survey of Exposure to Community Violence comprising a scale of Parental Victimization $(\mathrm{a}=.81)$ and a scale of witnessing violence $(\mathrm{a}=.84)$; the parental monitoring scale, the children's Depression Inventory; and the Hopelessness Scale for Children. They found that greater exposure to community violence was associated with more symptoms of depression and feelings of hopelessness, which are components of psychological trauma.

The children reported high rates of exposure to urban violence with their rates of witnessing violence (indirect victimization) being higher than personal (direct) victimization. Experience with personal victimization were found to be strongly and positively correlated with was a significant predictor of psychological trauma. This was manifested in children who had more experiences with personal victimization reporting more depression and 


\section{hopelessness.}

Lis-Turlejska (2008) investigated the presence of traumatic events and posttraumatic symptoms among 475 university students in Poland, comprising 325 females (69.4\%) and 143 males (31.1\%), with mean age of 22.9 and standard deviation of 3.89. Data were elicited from the participants with four measures; stressful life Events Screening Questionnaire used to measure life time exposure to a variety of traumatic events; Mississippi-C PTSD Scale measuring PTSD symptomatology; Impact of Event Scale used to measure subjective stress related to particular events; and Becks Depression Inventory used to measure symptoms of Depression. The findings showed that for exposure to traumatic events, majority of the participants, (345 students, $(75.6 \%)$ experienced at least one potentially traumatic event in line with the criterion AI of the PTSD diagnosis. The findings further revealed that multiple exposures are associated with a significantly higher risk of posttraumatic symptoms.

In Africa, Tumuti and Wang'eri (2014) examined trauma types, symptoms manifestations and social support systems among university students' trauma survivors in Kenya. Data were collected with a paper based questionnaire from randomly sampled 438 students, comprising 228 (25.1\%) males and 206 (47.7\%) females. The results of the study indicated that a large number of students $(45.16 \%)$ experienced traumatic events, with more males than females reporting having experienced traumatic events. It was also found that the most significantly reported traumatic events were witnessing violence, having a chronically sick family member, and facing situation in which they narrowly escaped death.

Engelbrecht (2009) examined the relationship between exposure to violent crime, traumatic stress symptomatology, and fear of crime in a sample of 216 first-year university students at the university of the Witwatersr and in Johannesburg, South Africa. The participants comprised of 166 (76.85\%) females and 50 $(23.15 \%)$ males, with a mean age of 18.51 years. The instruments used for data collection were Measure for Exposure to Violent Crime Impact of Event Scale- Revised and Fear of Crime Measure. The result showed high levels of exposure to violent crime, which includes direct and indirect exposure. On traumatic stress symptomatology, the researcher found moderate levels of traumatic stress symptom, with at least $20 \%$ of the total sample reporting traumatic stress symptomatology of clinical concern. The results also showed that fear of crime spread widely in the sample, at fairly high levels, with fear increasing markedly at night time.

In Nigeria, Yekeen (2010), reported a number of empirical studies carried out on the youths of the NigerDelta regions. In a study of 79 Bayelsa and Ondo States youths aged 18-38 years, an adapted Adolescent SelfReport Trauma Questionnaire was used to determine the participants' exposure to violent events while the PTSD Symptoms Scale by Foa, Riggs, Dance, and Rothbaum (1993), was used to determine the respondents' reactions to the exposure. The findings as reported by Yekeen (2010), revealed a mean of 38 crimes experienced by the participants, and that approximately $55 \%$ of the sample had witnessed a shooting. It was also found that the mean number of PTSD symptom for the total sample was 10 , while $77 \%$ of the respondents met full DSM-diagnostic criteria for PTSD.

Another study also reported by Yekeen (2010) which was carried out on the youths of the Niger Delta region of Abia and Akwa Ibom States, examined the exposure of 120 youths (60 each from each State) to community crime. A structural clinical interview was used to elicit data from the participants. The result of the study showed that all the participants had been exposed to community violence. While $50 \%$ of them reported having been a victim, $45 \%$ reported being a witness to at least one killing. Findings on the effects of the exposure showed that dysthymia was the most disorder diagnosed among the youths (31.6\%), followed by PTSD (21.6\%), major depression $(6.6 \%)$ and conduct disorder (1.6\%). In general, $40 \%$ of the participants were diagnosed with one or more psychiatric disorders, $42 \%$ reported psychiatric symptoms but did not meet the criteria for a specific psychiatric disorder, while 18\% reported no symptoms. Gaidam, Njoku and Bako (2010), investigated prevalence and nature of sexual assault among female students in a tertiary institution in Maiduguri, Nigeria.

They found out that the rate of sexual assault (violent crime) among the participants was high and that it was associated with physical and psychological trauma. A close ended, self-administered questionnaire was administered to 400 female students in University of Maiduguri, $349(87.3 \%)$ of whom were single and within the age bracket of $20-24$. The results showed that $35.6 \%$ of the sample had extra-genital trauma, $24.9 \%$ had psychological trauma, and $15.6 \%$ sustained genital trauma.

Ehigie and Mobolaji (2014), investigated the influence of experienced traumatic event(s) and place of residence (on campus/ off campus) on level of fear among 281 (65.5\%) males and 34.5\% females) university students in Nigeria. The respondents were grouped according to age range.128(45.6\%) were between 16-20 years old, $126(44.8 \%)$ were between 21-25 years old, 18 (6.4\%) were between 26-30 years old, and $9(3.2 \%)$ were 30 years old and above. Fear of crime scale developed by Ferraro in 1995 was used to collect data from the participants. The result showed that traumatic event(s) had significant positive with fear of crime and that place of residence had a significant main influence on fear of crime, and students who reside off-campus were found to report higher fear of crime. Further analysis showed that place of residence and traumatic event(s) have no significant interactive effect on fear of crime. 


\section{Statement of the problem}

Literature provided substantial evidence across nations to show prevalence of exposure to crime (Huntington, 2012, Milligan, 2010, Lis-Turlyska, 2008, Weaver, 2005, fear of crime (Woolnough, 2015), and psychological trauma (Rosenthal \& Schreiner, 2010; Yekeen, 2010) among undergraduate students and the adverse impact of these variables on their psychological wellbeing. There is the need to replicate these studies in Nigeria, given the fact that most of these studies were carried out with undergraduate students in the western world.

Furthermore, students are often exposed to various types of violence on campus. Female students are exposed to rape from armed robbers who often attack students hostels. The issue of cult rivalry and cult attacks and also parts of the campus violence that students do encounter. There are several other instances

Indeed, both direct and indirect exposure have the potential to cause fear of crime. For instance, observation shows that students rarely chose universities in Boko Haram areas. In the same way, fear causes them to boycott some places or activities that would otherwise promote their wellbeing and academic performance. Fear may have pushed some students especially the male students into drug-taking and enlistment into dangerous cults. Paradoxically, this creates a cycle of violence.

Finally, unfortunately in Nigeria, especially, Anambra State, not many studies have been done in this area, particularly among adolescent students. There is therefore the need for more empirical literature in this area, hence the need for this study. Based on the foregoing, the study provided answers to the following Questions.

\section{Research Questions}

1) Would there be a positive relationship between exposure to violence and psychological trauma among undergraduate students?

2) Would there be a positive relationship between fear of crime and psychological trauma among undergraduate students?

\section{Purpose of the Study}

The major purpose of this study was to examine the correlation between exposure to violent crime, fear of crime and psychological trauma among undergraduate students in Nnamdi Azikiwe University, Awka Nigeria. Specifically, the study seeks:

1) To examine the relationship between exposure to violent crime and psychological trauma.

2) To examine the relationship between fear of crime and psychological trauma.

\subsection{Hypotheses}

1) There will be a positive relationship between exposure to violent crime and psychological trauma.

2) There will be a positive relationship between fear of crime and psychological trauma.

\subsection{Method}

\section{Participants}

Two hundred and sixty- eight (268) participants who indicated that they were exposed to violent crime in the last 12 months participated in the study. They comprised of $127(47.4 \%)$ males and $141(52.6 \%)$ females whose ages ranged from 18 to 32 years, with a mean age of 23.8 years and standard deviation of 2.3. They were selected using multi-stage sampling technique. The four faculties were selected through simple random sampling technique.

\section{Instrument}

The following three instruments were used to elicit data from the participants: Measure for Exposure to violent crime (Engelbrecht, 2009). Impact of Event Scale- R (harowitz et. Al 1997) and Fear of crime measure developed by Van Klemperer (2009). The reliability and validity of the instrument were ascertained and confirmed. Confirmatory Factor Analysis Yielded acceptable factor loadings. Their reliability coefficients all above .75.

\section{Procedure}

A confirmatory pilot study was conducted, using 41 undergraduate students of University of Nigeria, Nsukka, comprising 19 males and 22 females. Their ages ranged from 17-32 years, with a mean age of 21.2 and standard deviation of 3.37. Overall coefficient of .89 was obtained for Impact of Event Scale, and .76 for Fear of crime measure.

The instruments were administered to the participants within a space of one week on each day of administration, the research team waited for the students to fill the questionnaire and retrieve them same day. On completion, the questionnaire were scored and analysed.

\section{Design and Statistics}

The study was a Survey that adopted a correlational design. The study further made use of Pearson Product Moment Correlation Statistics for data analysis. 


\section{Result}

Table 1. Summary Table of Correlation between Exposure to violent crime and Psychological Trauma

\begin{tabular}{|l|l|l|l|l|l|}
\hline & $\mathrm{N}$ & $\begin{array}{l}\text { EXPOSURE TO } \\
\text { VIOLENT CRIME }\end{array}$ & $\begin{array}{l}\text { PSYCHOLOGICAL } \\
\text { TRAUMA }\end{array}$ & P-VALUE & DECISION \\
\hline $\begin{array}{l}\text { Exposure to } \\
\text { violent crime }\end{array}$ & 268 & $.366^{* *}$ & .000 & Sig \\
$\begin{array}{l}\text { Psychological } \\
\text { Trauma }\end{array}$ & 268 & $.366^{* *}$ & & & \\
\hline
\end{tabular}

Result in table 1 above shows a significant positive relationship between exposure to violent crime and Psychological trauma, r.(268)=.366, P-value $<0.05$. Therefore, hypothesis one was accepted.

Table 2: Summary Table of Correlation between fear of crime and Psychological Trauma

\begin{tabular}{|l|l|l|l|l|l|}
\hline & $\mathrm{N}$ & $\begin{array}{l}\text { FEAR } \\
\text { CRIME }\end{array}$ & $\begin{array}{l}\text { PSYCHOLOGICAL } \\
\text { TRAUMA }\end{array}$ & P-VALUE & DECISION \\
\hline FEAR OF CRIME & 268 & & $.596^{* *}$ & .000 & Sig \\
$\begin{array}{l}\text { Psychological } \\
\text { Trauma }\end{array}$ & .268 & $.596^{* *}$ & & & \\
\hline
\end{tabular}

The result in table 2 above shows a significant positive relationship between fear of crime and psychological trauma, r. $(268)=.596$, P-value $<0.05$. Therefore hypothesis 2 was also accepted.

\section{Discussion and Conclusion}

The study examined exposure to violent crime and fear of crime as correlates of psychological trauma among undergraduate students; testing two hypothesis. The result of the study showed a significant positive relationship between exposure to violent crime and psychological trauma. Therefore, hypothesis 1 was accepted and confirmed. This implies that the more the students are exposed to violent crime, the more they are psychologically traumatized. The result is consistent with the findings of Tumuti and Wang'eri (2014).

Geidam, Njoku and Bako (2012), and Lis- Turlejeska (2008), each od who found a significant positive relationship between exposure to violent crime and psychological trauma among university students. The result also confirms the positive relationship between two variables as found by Yekeen (2010) among both in- school and out of school youths in the oil rich conflict areas (Delta region) in Nigeria. The result negates no research findings known to the researchers. This is not surprising given the high wave of violent crime in the world today. In Nigeria for instance, the students, together with other Nigerians are daily exposed to all manner of violent crimes (Akeem, 2008) that often result to heavy casualties.

The result of positive relationship also was supported by the trauma theory as abbreviated by Bloom (1999), which postulates that human beings have the capacity to experience trauma because they are social beings who depend on one another for psychological wellbeing and survival. Therefore, any event that causes disruption in the relationship be it violent or non-violent crime or physical separation through death or disharmony can cause trauma in the victim.

The result also showed a significant positive relationship between fear of crime and psychological trauma; therefore, accepting and confirming hypothesis 2 . The result implies that the higher the level of fear of crime in the students, the higher the level of psychological trauma they experience. The findings is in consonance with the result of the study by Engelbrecht (2009), who found a positive relationship between fear of crime and traumatic symptomatology among undergraduate students in South Africa. The result is also in tandem with the study by Grinshetyn (2013) which confirmed the hypothesis that fear of neighbourhood crime resulted to increase in scores made by adolescent participants on anxiety/depression subscale.

Again, the result by implication confirms the finding by Ehigie and Mobolaji (2014), which showed that traumatic event(s) had significant positive relationship with fear of crime; which implied that students who experienced more traumatic events exhibited increased fear of crime and vice versa.

In conclusion, exposure to violent crime correlates positively and significantly with psychological trauma. Thus, high exposure of the students to violent crime will lead to prevalence of high level of psychological trauma in them.

Fear of crime is also a correlate of psychological trauma among undergraduate students who were exposed to violent crime. The two variables have significant positive correlation. This implies that higher level of fear among the undergraduate students will bring about an increase in level of psychological trauma in the students.

\section{Implications of the study}

The findings of this study have far reaching implications for policy makers, university administrators and councillors, parents and undergraduate students. The study provides empirical evidence of the significantly 
positive correlations between exposure to violent crime, fear of crime and psychological trauma. The implication of this findings include urgent response from policy makers to strengthen and improve on their security services in the general society and around and within school/university environments.

The university administrators and councillors as a matter of urgency should develop programmes that will aim at reducing fear of crime among victims and also helping the already traumatized.

The counsellor/therapist should be available to students, being aware, through these findings of how easily students can be traumatized by both exposure to violent crime and fear of crime, bearing in mind that society is riddled with violent crimes.

Parents are expected to be more attentive their adolescent students, watching out for early signs of behavioural, cognitive or physical symptoms of trauma in their children. Seeking helps early enough will save a lot of damages. This finding have implication for students who should be mindful of where they go, what they do and the persons they move and associate with in order to curtail opportunities for exposures.

\section{Recommendations.}

Some far reaching recommendation were proffered on the basis of the findings of the study.

1) Educational policies should be such that encourage and enable self-sustenance after secondary or tertiary education. This will check to a great extent the massive unemployment among the youths, which according to literature is one of the major contributors to high crime wave in the country. Right value orientation should also be inculcated in the students decrying insatiable appetite for wealth, titles and fame based on display of wealth.

2) Private possession of firearms should be checked with all the seriousness and urgency it demands.

3) Intervention programmes should be developed for victims of psychological trauma and fear of crime.

4) University should have functional counselling or therapeutic centres managed by qualified professionals in the mould of clinical psychologist, councillor or psychotherapist.

\section{References}

Agbu, O. (2003). Oil and environmental conflict in Nigeria's Niger-Delta. Paper presented on the Nigeria society under democratic rule, 11999-2003, University of Ilorin, Nigeria (20 $0^{\text {th }}-21$ ist August).

Akeem, A.G. (2008). Circumscribing conflict in the resources endowed Niger Delta Communities of Nigeria. http://www.Iumes.lu.se/student99/stanley,w/econspaper/28sheet.pdf Retrieved12/06/15.

Australian Psychological Society (APS)(2015). Understanding and managing psychological trauma. http://www.psychology.org.au/publications/tipsheets/trauma/Retrieved 16/06/15

Beaulac, J; Bouchard,D, \& Kristian, E. (2013). Physical activity for adolescents living in disadvantaged neighbourhood: Views of parents and adolescents on needs barriers, facilitators, and programming. Leisure 249,537-561.

Bloom, S.L. (1997). Creating Sanctuary: Towards the evolution of same Societies. New York: Routledge.

Ceballo, R, Ramerz, C; Hearn, K.D; \& Maltese, K.L (2003). Community Violence and Children's psychological wellbeing: Does parental monitoring matter? Journal of clinical child and Adolescent Psychology, 32(4),586592.

Ehigie, B.O; \& Mobolayi, F.T. (2014). Influence of traumatic event(s) and location of residence on fear of crime: A case study of undergraduate students in Nigeria. Academic Journal, 6(11), 138-144.

Engelbrecht, S.K. (2009). Exposure to violent crime, fear of crime, and traumatic stress symptomatology (Unpublished Master's Thesis) University of the Witwatersand, Johannesburg, South Africa.

Foa, E; et al. (1993). Reliability and Validity of a brief instrument for assessing posttraumatic stress disorder. Journal of Traumatic Stress, 6,459-473.

Garofalo, J. (1981). The Fear of Crime: causes, and consequences. Journal of criminal law and criminology, $72,839-857$

Geidam, A.D; Njoka, A.E; \& B. (2010). Prevalence and nature of sexual assault among femal students in a tertiary institution in Maiduguri, Nigeria. A cross-sectional study. International Journal of Research, 3(4), 199-203.

Gianconia, R.M; Reinherz, H.Z, Silverman, A.B, Pakiz, B, Frost, A.K \& Cohen, E. (1995). Trauma and posttraumatic stress disorder in a community population of older adolescents. Journal of the American Academy of child and Adolescent Psychiatry. 34(10), 1369-1380.

Giller, E. (1999). What is psychological trauma? A paper presented at the annual conference of Maryland Mental Hygiene Administration Passages To Prevention Across Life's Spectrum, May, 1999.

Grinshteyn, E. (2013). Causes and consequences of fear of crime, impact of fear of crime on behavioural health outcomes and behavioural health treatment among adolescents (Unpublished Doctoral dissertation) University of California, Los Angeles.

Huntington, J.S.(2012). Impact of exposure to violence on urban youth: A biopsychosocial perspective of aggression. (Unpublished Doctoral Dissertation) Section Hall University. 
Lawler, C; Quimette, P; \& Dahlsedt, D. (2005) Posttraumatic stress symptoms, coping, and physical status among university students seeking health care. Journal of Traumatic Stress, 18(6), 741-750

Lis-Turlejska, M.(2008). Prevalence of traumatic events and posttraumatic stress symptoms in a student sample in Poland. Torture, 18(1), 12-18.

Miethe, T.D; Stafford, M.C; \& Long, J.S (1987). Social differentiation in criminal victimization: A test of routine activities/lifestyle theories. American Sociological Review, 52(2), 184-194. http://www.jastor.org/table/2095447. Retrieved 27/10/15.

Milligan, E.(2010). School violence exposure and adolescent substance use (unpublished masters Thesis), University of Florida.

Mrug,S, Loosier,P; \& Windle, M. (2008). Violence exposure across multiple contexts, individual and joint affects on adjustment. American Journal of Orthopsychiatry. 98(1), 70-84.

Nigerian Stability and Reconciliation Programme (NSRP)(2014). Fourth Report on Violence in Nigeria (200062014) Nigeria Watch www.nsrp-nigeria.org. Retrieved 12/06/15.

Pretories, R. (2008). Armed robbery, violent assault and perceptions of personal insecurity and social society as a risk. Acta criminological, 21(2)81-91.

Psychological Care \& Healing (PCH)(2015) Treatment Centre. Psychological or emotional trauma. http:// or www.pchtreatment.com/psychological-trauma/Retrieved 17/06/15.

Rosenthal, B.S; \& Schreiner, A.C (2010). Prevalence of psychological symptoms among University undergraduate students in an ethnicity diverse urban public college. www.tandfonlin.com/doi/abs/10.10800/074484800096277.

Seery, M.D. (2011). Tough times can make you tougher. http://psychcentral.com/news/2011/10/19/tough-timescan-make-you-tougher/32739. Hemi-Retrieved 26/06/2015.

Truman, J.(2005). Predictors of fear of crime and the relationship of crime rates and fear of crime Undergraduate Research Journal, 1, 18-27.

Timute, S, \& Wang-eri, T. (2014). Trauma types, symptoms manifestations and social support systems among university students trauma survivors in Kenya International Journal of Educational and Research, 2,(5), 1330.

Van Klempoerer, A. (2009). Relationship between fear of crime, proximity of trauma exposure and self-capacities. (Unpublished Master's Thesis). University of Witwaterstrand, Johannesburg, South Africa.

Weaver, C.M. (2005). Violence breeds violence: childhood exposure and adolescent problems (Unpublished Master's Thesis) University of Notre Dame.

Woolnough, A.D. (2015). Fear of crime on campus: Gender differences in use of self-protective behaviours at an urban university. www.pa;graire.journals.com/si/jornal/v.22/ni/fullsj2008iia.html.Retrieved 23/06/2015.

Yekeen, A.J. (2010). Exposure to Community Violence: Niger Delta Youth, Posttraumatic Stress reactions and treatment implications. Journal of Alternative Perspectives in The Social Sciences, 2(2), 917-931. 